Supplement of The Cryosphere Discuss., 9, 4845-4864, 2015

http://www.the-cryosphere-discuss.net/9/4845/2015/

doi:10.5194/tcd-9-4845-2015-supplement

(C) Author(s) 2015. CC Attribution 3.0 License.

(c) (1)
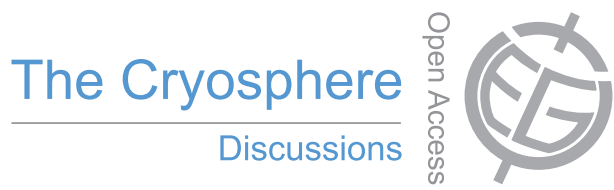

Supplement of

\title{
Tomography-based observation of sublimation and snow metamorphism under temperature gradient and advective flow
}

\section{P. P. Ebner et al.}

Correspondence to: M. Schneebeli (schneebeli@slf.ch)

The copyright of individual parts of the supplement might differ from the CC-BY 3.0 licence. 
ota 1

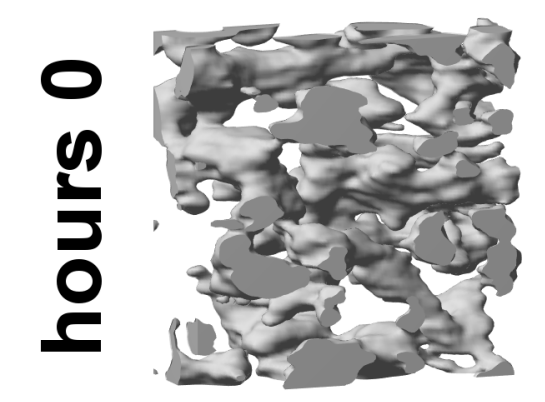

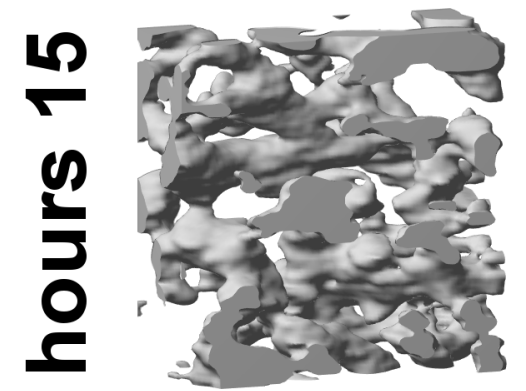

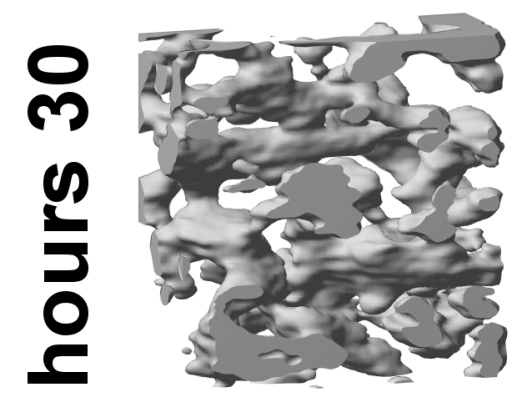

18 is

क $50-3$

3 we

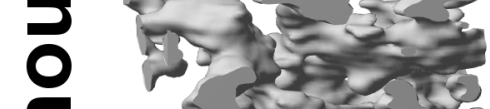

ع

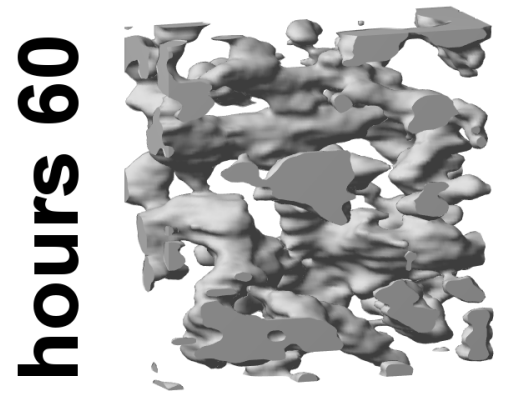

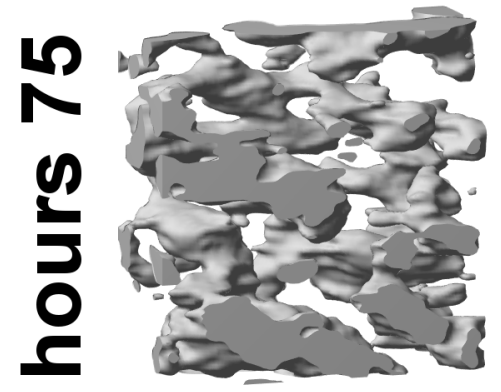

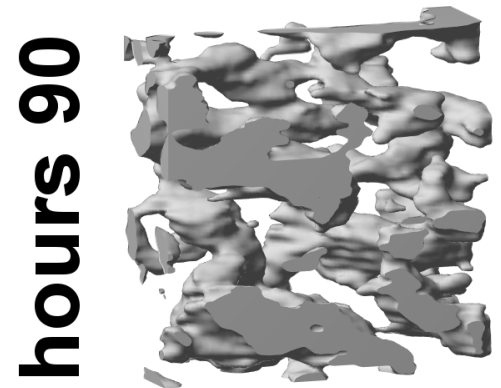

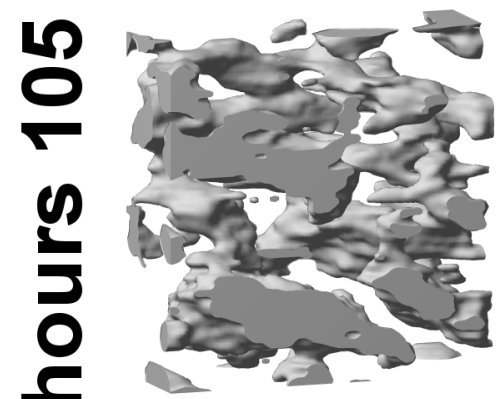

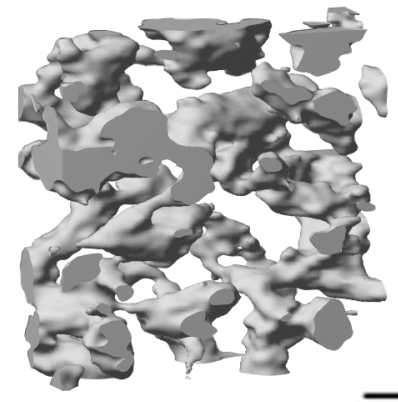

$1 \mathrm{~mm}$
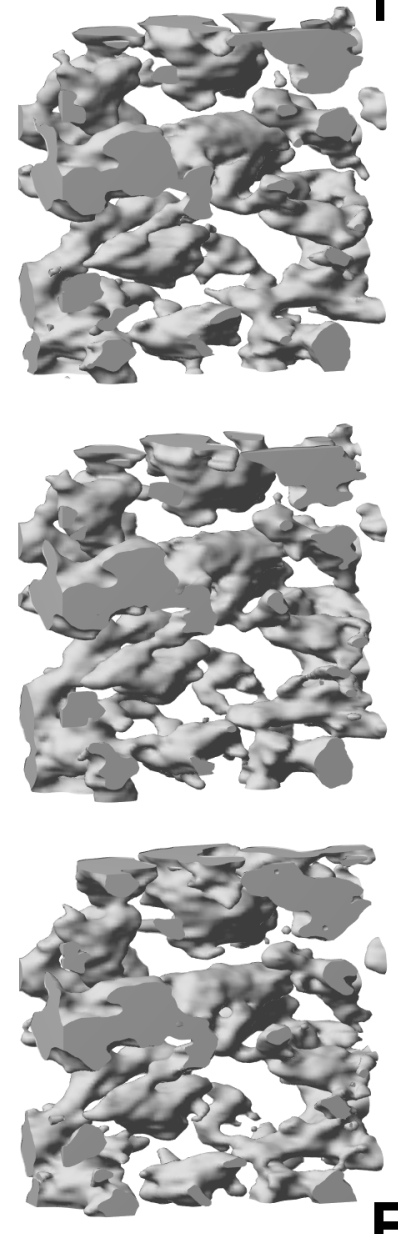

\section{Flow}
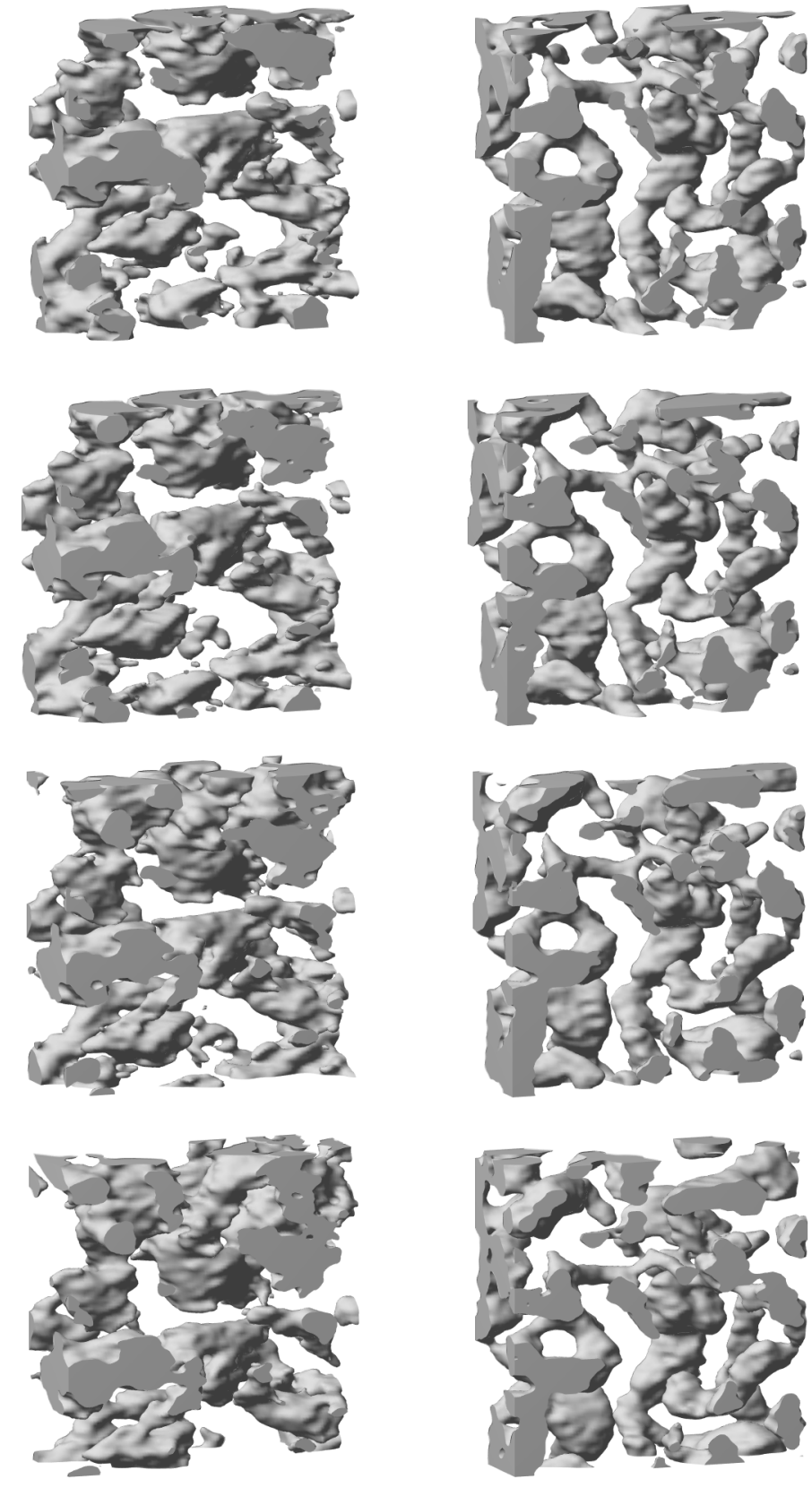

ota 4
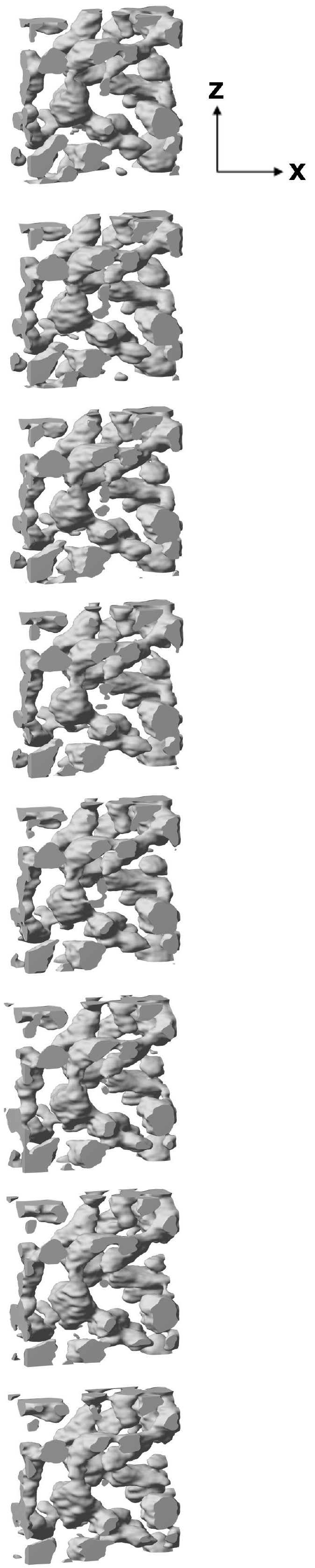


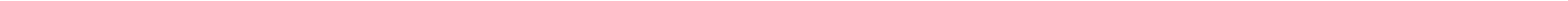

